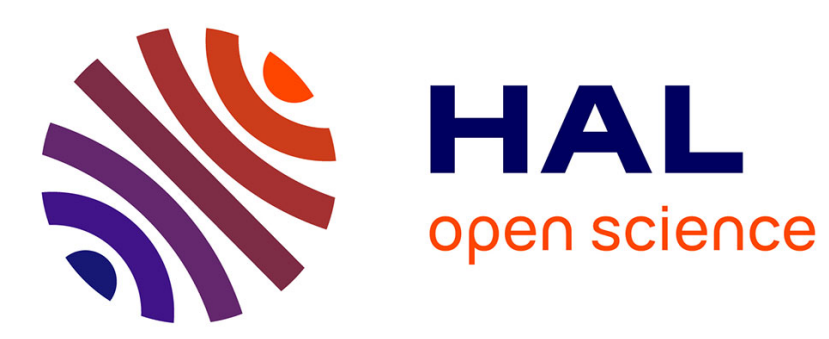

\title{
Françoise en 1950 et Élodie en 2011, ou les métamorphoses des modes de vie
}

Gérard-François Dumont

\section{To cite this version:}

Gérard-François Dumont. Françoise en 1950 et Élodie en 2011, ou les métamorphoses des modes de vie. Population et avenir, 2011, 701, pp.18-19. 10.3917/popav.701.0018 . halshs-00770084

\section{HAL Id: halshs-00770084 https://shs.hal.science/halshs-00770084}

Submitted on 24 Jan 2018

HAL is a multi-disciplinary open access archive for the deposit and dissemination of scientific research documents, whether they are published or not. The documents may come from teaching and research institutions in France or abroad, or from public or private research centers.
L'archive ouverte pluridisciplinaire $\mathbf{H A L}$, est destinée au dépôt et à la diffusion de documents scientifiques de niveau recherche, publiés ou non, émanant des établissements d'enseignement et de recherche français ou étrangers, des laboratoires publics ou privés. 


\section{Françoise en 1950 et Élodie en 2011 ou Les métamorphoses des modes de vie}

Par GérardFrançois DUMONT

1. Ce tableau comparatif s'inspire en partie de la méthode de Jean Fourastié entre deux moundes Mémoires deux mondes. Memoires en forme de dialogues avec sa fille Jacqueline Posthume, avec la collaboration de Jacqueline Fourastié et Béatrice Bazil, Beauchesne éditeur, Paris,1994. p. 271 et s.

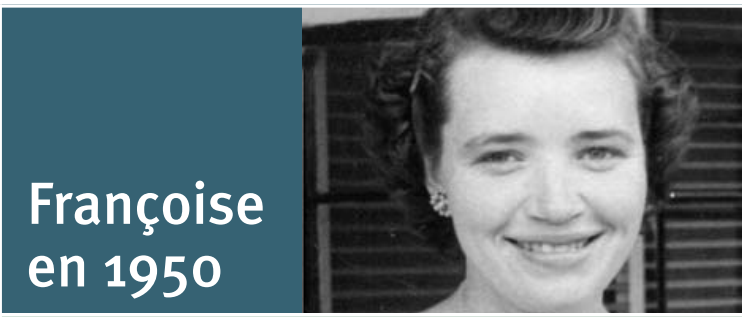

Elle appartient à une fratrie de 3 enfants. Parmi ses vingt frères et sœurs, cousines ou cousins germains, l'un est mort quelques jours après sa naissance.

Les couches en tissu des bébés doivent être soigneusement lavées après chaque usage.

Son frère dort dans un lit-cage que l'on déplie chaque soir dans un coin du séjour.

En 1950, l'espérance de vie à la naissance d'une femme est de 69 ans en France.

Pour la femme ayant atteint l'âge de 60 ans en 1950, l'espérance de vie restante est de 18 ans.

Dans le quartier où elle habite, Françoise connaît des personnes qui ont dû partir soigner leur tuberculose dans un sanatorium (il y en a au moins un par département).

Dans le quartier où elle habite, Françoise connaît des enfants qui souffrent de la poliomyélite.

Elle ne connaît que deux de ses grands-parents.

Elle entend souvent parler de maladies incurables et connaît plusieurs personnes jeunes décédées suite à une infection.

Ses sous-vêtements sont lavés dans une lessiveuse. Certaines de ses tantes continuent à aller au lavoir.

Une fois par semaine, il faut aller se doucher dans les cabines des bains-douches, car il n'y a pas de salle de bains dans les logements, juste une salle d'eau.

Les ordures ménagères sont mises dans de grosses poubelles rondes en métal fermées par un couvercle. Le ramassage effectué au petit matin fait beaucoup de vacarme.

Il faut, ce qui est souvent épuisant, monter au logement par l'escalier de l'immeuble, puisque ce dernier n'a pas d'ascenseur.

Sa cousine qui vit à la campagne effectue chaque jour plusieurs kilomètres de marche pour rejoindre l'école. Elle porte un morceau de pain et un bout de fromage pour son déjeuner et, en hiver, un morceau de bois pour nourrir le poêle de la classe.

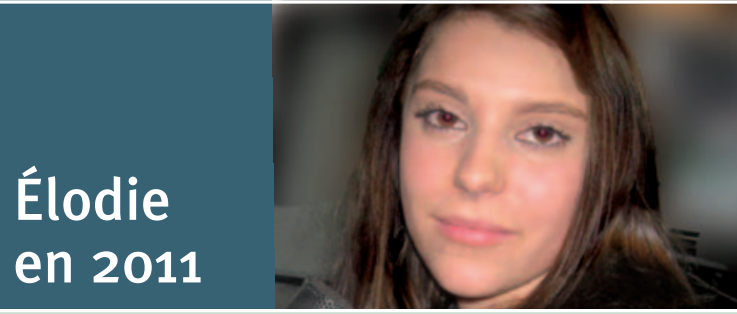

Elle appartient à une fratrie de 2 enfants. Elle connaît tous ses frères et sœurs, cousines ou cousins germains. En effet, la mortalité infantile est quatorze fois plus faible qu'en 1950. Les couches absorbantes sont faciles à changer et jetables après usage.

Elodie et son frère ont chacun leur chambre.

En 2011, l'espérance de vie à la naissance d'une femme est de 84 ans en France.

Pour la femme ayant atteint l'âge de 60 ans en 2011, l'espérance de vie restante est de 27 ans.

Depuis les années 1950, les antibiotiques ont fait disparaître la tuberculose en France et les sanatoriums ont été reconvertis. Toutefois, la tuberculose est légèrement réapparue en France en raison de migrations ou sous les effets du sida.

Depuis les progrès de l'hygiène et surtout la vaccination, la poliomyélite a disparu et son éradication est officielle sur tout le continent américain, en Europe et dans les régions du Pacifique occidental.

Elle connaît ses quatre grands-parents et même un arrièregrand-parent.

Avec le développement des antibiotiques, de nombreuses maladies ne sont plus mortelles et les maladies incurables sont en net recul.

Ses sous-vêtements sont lavés dans un lave-linge à haute température pour tuer les microbes et séchés dans un sèche-linge.

Il est possible de prendre une douche tous les jours et un bain lorsqu'on le souhaite, puisque le logement est équipé.

Les ordures ménagères sont triées dans des bacs en matière plastique à roulettes, peu bruyants, saisies mécaniquement par les camions de ramassage.

Pour monter dans l'appartement, on prend l'ascenseur.

Sa cousine qui vit à la campagne bénéficie du ramassage scolaire, son école est équipée du chauffage central et elle mange à la cantine subventionnée pour les familles en difficulté. 